\title{
Low Activation-Modified High Manganese-Nitrogen Austenitic Stainless Steel for Fast Reactor Pressure Vessel Cladding
}

\author{
Aly Saeed ${ }^{1}$, Raed Mohmed El-Shazly ${ }^{2}$, Saeed Nabil Ghali ${ }^{3}$, Samir Yousha El-khamisy ${ }^{4}$, \\ Soad Abd El-Moneem El-fiki ${ }^{4}$, Mamdouh Mahmoud Eissa ${ }^{3}$ \\ ${ }^{1}$ Nuclear Power Stations Department, Faculty of Engineering, Egyptian-Russian University, Cairo, Egypt \\ ${ }^{2}$ Physics Department, Faculty of Science, Al-Azhar University, Cairo, Egypt \\ ${ }^{3}$ Steel Technology Department, Central Metallurgical Research and Development Institute (CMRDI), Helwan, Egypt \\ ${ }^{4}$ Physics Department, Faculty of Science, Ain Shams University, Cairo, Egypt
}

Email address:

aly_8h@yahoo.com (A. Saeed)

\section{To cite this article:}

Aly Saeed, Raed Mohmed El-Shazly, Saeed Nabil Ghali, Samir Yousha El-khamisy, Soad Abd El-Moneem El-fiki, Mamdouh Mahmoud Eissa. Low Activation-Modified High Manganese-Nitrogen Austenitic Stainless Steel for Fast Reactor Pressure Vessel Cladding. Nuclear Science. Vol. 3, No. 3, 2018, pp. 45-51. doi: 10.11648/j.ns.20180303.14

Received: September 20, 2018; Accepted: October 25, 2018; Published: November 21, 2018

\begin{abstract}
Low and free nickel austenitic stainless steel alloys were developed successfully and proposed to be used as a liquid sodium coolant fast reactor pressure vessel cladding. A standard austenitic stainless steel SS316L (AISI 316L) was produced as a reference sample. The nickel content was partially or totally replaced by manganese and nitrogen. The microstructure of the produced stainless steel alloys was investigated using Schaeffler diagram, optical microscopy and X-ray diffraction patterns (XRD). Mechanical properties of the developed stainless steel grads were investigated using Vickers hardness, impact and tensile tests at room temperature. Sodium chloride was used to study the corrosion rate of the investigated alloys by open circuit potential technique. Slow and total slow neutrons removal cross sections were measured using ${ }^{241} \mathrm{Am}-\mathrm{Be}$ neutron source and highly calibrated He-3 detector. Eight gamma ray lines which emitted from ${ }^{60} \mathrm{Co}$ and ${ }^{232} \mathrm{Th}$ radioactive sources and HPGe detector were used to study the attenuation parameters of the produced alloys. Metallography, Schaeffler diagram and XRD results showed that all the produced stainless steels are mainly of austenite phase with a small ferrite phase. The developed manganese-nitrogen stainless steels showed higher hardness, yield and ultimate tensile strength than SS316L. The elongation of developed stainless steels is relatively lower than the standard SS316L. The impact toughness was reduced with replacement of $\mathrm{Ni}$ by $\mathrm{Mn}$. The developed manganese stainless steels have a higher total slow removal cross section than SS316L. On the other hand, the slow neutron and gamma rays have nearly the same behavior for all studied stainless steels.
\end{abstract}

Keywords: Reactor Materials, Mn-N Stainless Steel, Structural and Mechanical Properties

\section{Introduction}

The thorny issue in the nuclear power reactor operating is the continuously keeping of the desired safety and reliability level. The safety is always achieved by the selection of suitable materials for the different reactor regions. [1] The reactor pressure vessel (RPV) is an integral part of the reactor coolant pressure boundary. Pressure vessels are typically fabricated from thick carbon steel and cladded with austenitic stainless steel or Inconel. The purpose of the clad is to protect the carbon steel from the environment in the vessel such as high temperature and corrosion. [2-3] Austenitic stainless steel containing nickel and Inconel alloys face a large numbers of problems such as He- embritllement and long lived nuclides as a waste material. [4-5] Hence, the alloys containing nickel should be minimized or eliminated from the reactor core. In this regard, low activation austenitic manganese-nitrogen stainless steels have raised interest as an alternative to austenitic nickel stainless steels and Inconel alloys. [6] The high manganese-nitrogen stainless steels have attracted interest because they are potentially less expensive and less activity than nickel stainless steels. Manganese is an important element in stabilizing the austenite structure. 
Manganese is probably the most important element after carbon that is commonly used to increase hardness and strength of the steels. Additionally, manganese refines the produced microstructure due its depression of transformation temperature, besides its ability to decrease the critical cooling rate during hardening. [7-8] Nitrogen is a very effective austenite forming element that enlarges the austenite phase field on a phase diagram on the expense of ferrite. [9] Beside the strong stability effect on the austenitic structure, other benefits of nitrogen have been appeared. The attractive combination of properties of nitrogen stainless steels; increased strength, toughness, creep and wear resistance, excellent corrosion properties that allow characterizing them as a promising class of engineering materials. The previous works report on the favorable influence of nitrogen on the strength and corrosion behavior, low-temperature properties and creep behavior of austenitic steels. Nitrogen decreases pitting susceptibility of stainless steels and enhances the resistance of steels against stress corrosion cracking. [10-12]

On the basis of the aforementioned aspects, the present study is focused on developing a new high manganesenitrogen stainless steel alloy for fast reactor pressure vessel cladding. The effects of replacing $\mathrm{Ni}$ by $\mathrm{Mn}$ and $\mathrm{N}$ on microstructure, mechanical, corrosion along with neutron and gamma ray attenuation properties of the manufacturing developed stainless steel grads were studied.

\section{Samples Preparation}

Series of experiments to replace the undesirable Ni content and produce low activation $\mathrm{Mn}-\mathrm{N}-\mathrm{Cr}-\mathrm{Fe}$ stainless steels were carried out. Attempts were designed to calculate the materials balance and the manganese-nitrogen content required for producing the desired low and free nickel austenitic stainless steel grads. The SS316L standard and three modified grades of low and free nickel, Mn-N-Cr-Fe, austenitic stainless steel grads were produced from high purity raw materials using a $30 \mathrm{Kg}$ pilot plant medium frequency induction furnace. The induction furnace melting unit was lined with basic lining. All melts were cast in iron moulds of inner diameter $70 \mathrm{~mm}$. The different steel grads were hot for two hours at temperature $1150^{\circ} \mathrm{C}$. The forged process was started at $1100^{\circ} \mathrm{C}$ by using load of two ton of free forging.

\section{Experimental Measurements}

The chemical compositions of the produced stainless steel alloys were analyzed using X-ray fluorescence (XRF) and spectrographic analysis (SPGA). Kjeldahl method [13] was used for determination of total nitrogen content in the produced stainless steel grads. An optical microscope was used in the microstructure examination of etched samples. The used etchant is composed of $5 \mathrm{ml} \mathrm{HCl}+2 \mathrm{gm}$ picric acid $+100 \mathrm{ml}$ Ethyl alcohols. X-ray diffraction was employed for identification of the constituent phases in the studied stainless steel alloys. Vickers hardness test was carried out on high polished stainless steel samples. The hardness measurements were carried out using Zwick-Roel hardness tester machine with $50 \mathrm{~kg}$ working load. An average of five readings was taken. Tensile test was carried out for the specimens at room temperature. Based on the tensile test, the yield strength, ultimate tensile strength and elongation were determined. Round tensile specimens were machined with dimensions according to ASTM-E8 specification. [14] The test was carried out using tensile machine (EZ20 $20 \mathrm{KN}$ ) with a cross head speed of $0.3 \mathrm{~mm} / \mathrm{min}$. The impact testing was performed using a Charpy-V/Izod impact tester, which provided the measured value (i.e. absorbed impact energy) through a mechanical dial. The impact test was performed on PKP450 impact testing machine. Each of the tensile and impact values was the average of two reading data. The effect of replacement of nickel by nitrogen and manganese on the corrosion resistance in $\mathrm{NaCl}$ medium was investigated using open-circuit potential method. The density of the produced stainless steels was measured using the standard Archimedes principle. [15] The ${ }^{3} \mathrm{He}$ neutron detector was used to detect the slow and total slow neutron energies emitted from ${ }^{241} \mathrm{Am}-$ Be neutron source with activity $5 \mathrm{Ci}$ and neutron yield $=(1.1-$ 1.4) $x 10^{7} \mathrm{n} / \mathrm{sec}$. In case of slow neutrons measurements the collimated beam was slowed down by Perspex material. The scheme of the experiment is shown in Figure 1.

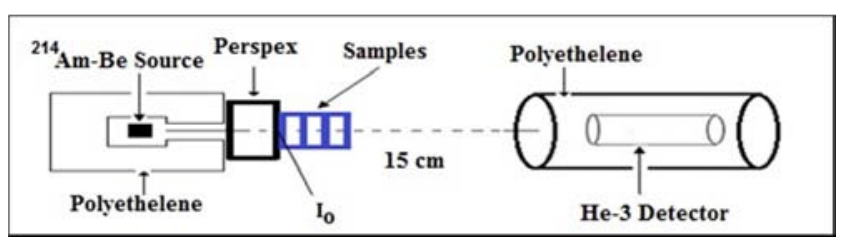

Figure 1. Schematic diagram of neutrons measurements.

The gamma ray attenuation coefficients of the produced stainless steel alloys were obtained for eight gamma energy lines $(238.63,338.28,583.19,911.2,968.97,1173.23$, 1332.49, and $2614.51 \mathrm{keV}$ ) emitted from ${ }^{60} \mathrm{Co}$ and ${ }^{232} \mathrm{Th}$ radioactive sources. Hyper Pure Germanium detector (HPGe) was used to measure the gamma ray intensities for the studied energy lines. Figure 2 shows the experimental setup. The obtained experimental results were compared with the theoretical data which calculated using the WinXCom computer program (version 3.1). [16]

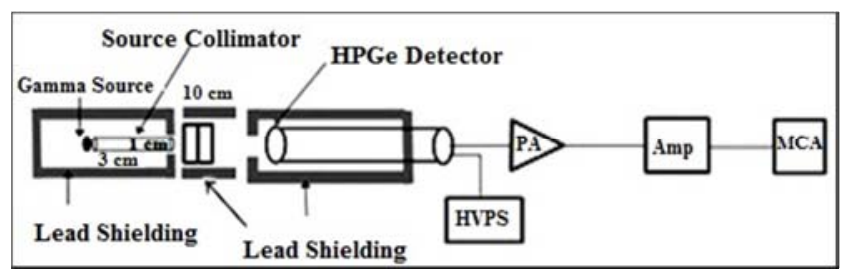

Figure 2. Experimental setup of gamma ray narrow beam transmission method.

\section{Results and Discussions}

The chemical compositions of the produced stainless steels are given in Table 1. It is clear that the produced stainless 
steel SS316L has a chemical composition within the range of standard stainless steel AISI 316L. SS 316 L stainless steel grad was developed through partial replacement of $\mathrm{Ni}$ by manganese and nitrogen as given in the SSMn6N-Ni and SSMn7N-Ni steels while $\mathrm{Ni}$ was completely replaced in
SSMn4N steel. It is worth mentioning also that the molybdenum was totally eliminated in the modified stainless steel grads because of the long life time of its nuclides. Additionally, were carefully to avoid any amount of long live time elements, cobalt and niobium.

Table 1. The chemical composition of investigated stainless steel grads.

\begin{tabular}{|c|c|c|c|c|c|c|c|c|c|c|c|c|}
\hline \multirow{2}{*}{ Steel Code } & \multicolumn{12}{|c|}{ Chemical composition, wt $\%$} \\
\hline & $\mathbf{C}$ & Mn & $\mathbf{S i}$ & $\mathbf{C r}$ & $\mathrm{Ni}$ & Mo & $\mathbf{V}$ & $\mathbf{T i}$ & $\mathbf{S}$ & $\mathbf{P}$ & $\mathbf{N}$ & $\mathbf{F e}$ \\
\hline SS316L & 0.02 & 1.22 & 1.94 & 16.41 & 9.89 & 2.00 & 0.115 & 0.246 & 0.010 & 0.010 & 0.030 & Balance \\
\hline SSMn6N-Ni & 0.11 & 6.31 & 2.06 & 20.75 & 5.30 & 0.04 & 0.090 & 0.004 & 0.009 & 0.004 & 0.225 & Balance \\
\hline SSMn7N-Ni & 0.09 & 7.01 & 2.89 & 20.09 & 3.49 & 0.02 & 0.090 & 0.004 & 0.008 & 0.008 & 0.240 & Balance \\
\hline SSMn4N & 0.12 & 3.84 & 2.59 & 20.67 & 0.11 & 0.02 & 0.062 & 0.003 & 0.010 & 0.009 & 0.235 & Balance \\
\hline
\end{tabular}

The optical micrographs of the produced stainless steel grads are shown in Figure 3. The examination of these photos shows numerous annealing twins which confirm the austenite phase of the produced stainless steel alloys. It was noticed that, the obtained photos of the investigated stainless steel grads contain a little ferrite grains. However, it is difficult to differentiate between the two phases (austenite and ferrite) through microscopic examination. Hence, in order to get more details on the observed optical microscope microstructure for the investigated stainless steel grads, Schaeffler diagram and $\mathrm{x}$-ray diffraction pattern were carried out.

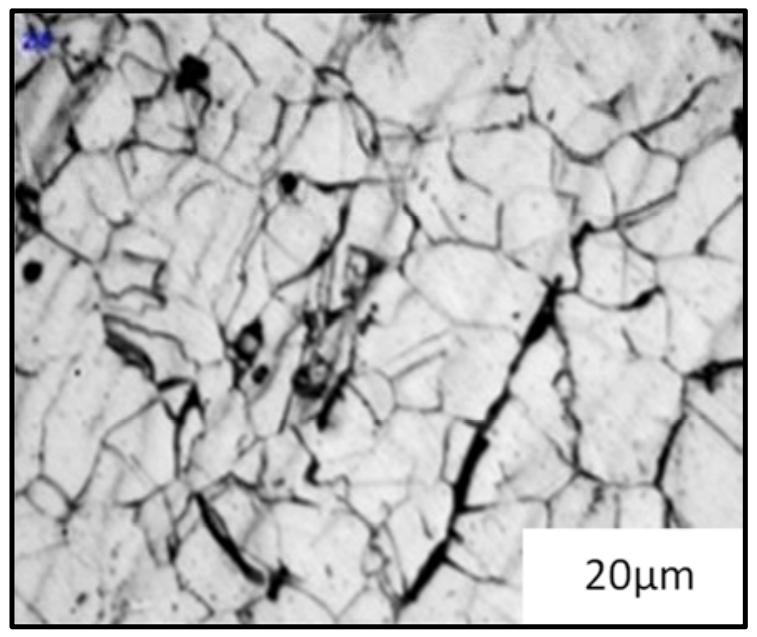

Steel SS316L

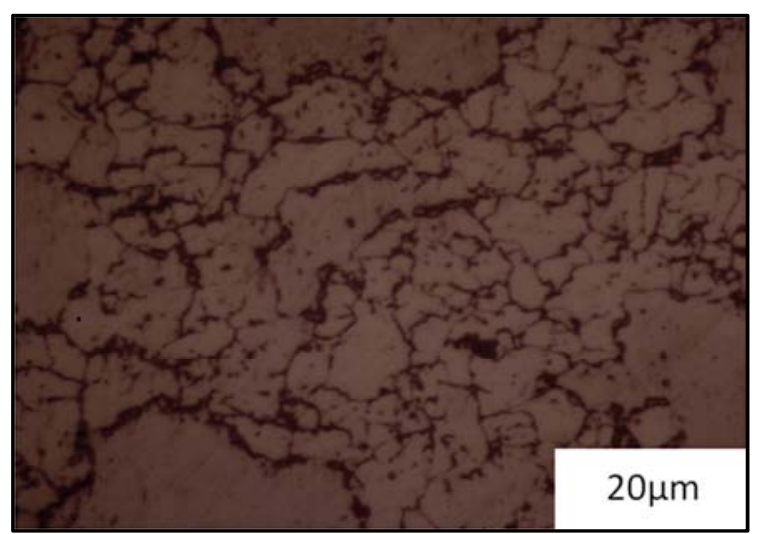

Steel SSMn4N

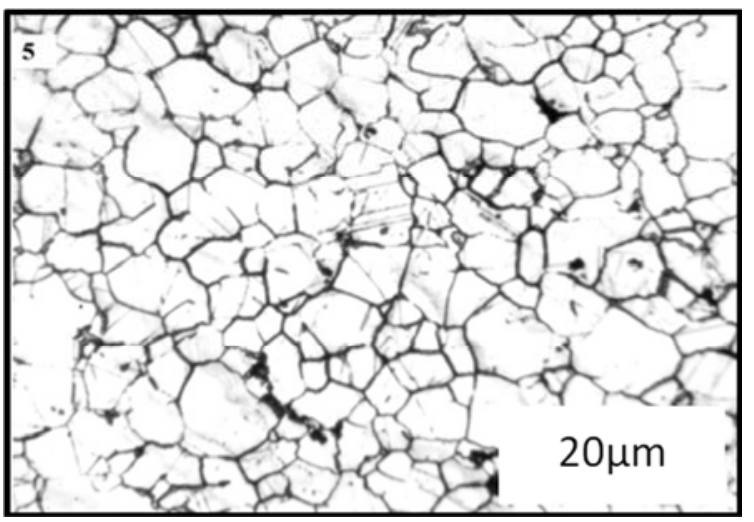

Steel SSMn6N

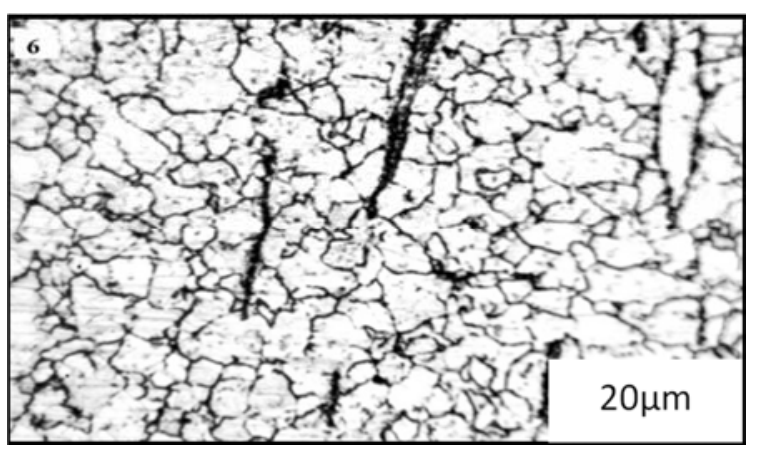

Steel SSMn7N

Figure 3. Optical micrograph of investigated stainless steels alloys.

$\mathrm{Ni}$ and $\mathrm{Cr}$ equivalents according to Schaeffler diagram of developed stainless steel grads can be calculated as following. [17]

$$
\begin{gathered}
\mathrm{Ni}_{\text {Equi. }}=\mathrm{Ni}+0.5 \mathrm{Mn}+30 \mathrm{C}+30 \mathrm{~N} \\
\mathrm{Cr}_{\text {Equi. }}=\mathrm{Cr}+2 \mathrm{Si}+1.5 \mathrm{Mo}+5 \mathrm{~V}+1.5 \mathrm{Ti}
\end{gathered}
$$

with all concentrations being expressed in weight percentages.

The obtained data of the calculated $\mathrm{Ni}$ and $\mathrm{Cr}$ equivalents are listed in Table 2 . 
Table 2. The calculated values of $\mathrm{Cr}$ and Ni equivalents of the investigated stainless steel grads.

\begin{tabular}{lllll}
\hline & SS316L & SSMn6N-Ni & SSMn7N-Ni & SSMn4N \\
\hline Cr Equivalent & 23.689 & 23.926 & 24.471 & 24.5995 \\
Ni Equivalent & 12 & 18.505 & 16.895 & 12.68 \\
\hline
\end{tabular}

The Schaeffler diagram as shown in Figure 4 predicts that the developed low nickel manganese-nitrogen stainless steel SSMn6N-Ni has a single austenite phase $(\gamma-$ Phase). While the developed manganese-nitrogen stainless steels SSMn7N-Ni, SSMn4N and standard stainless steel SS316L exhibit mainly austenite phase with low percentage of ferrite.

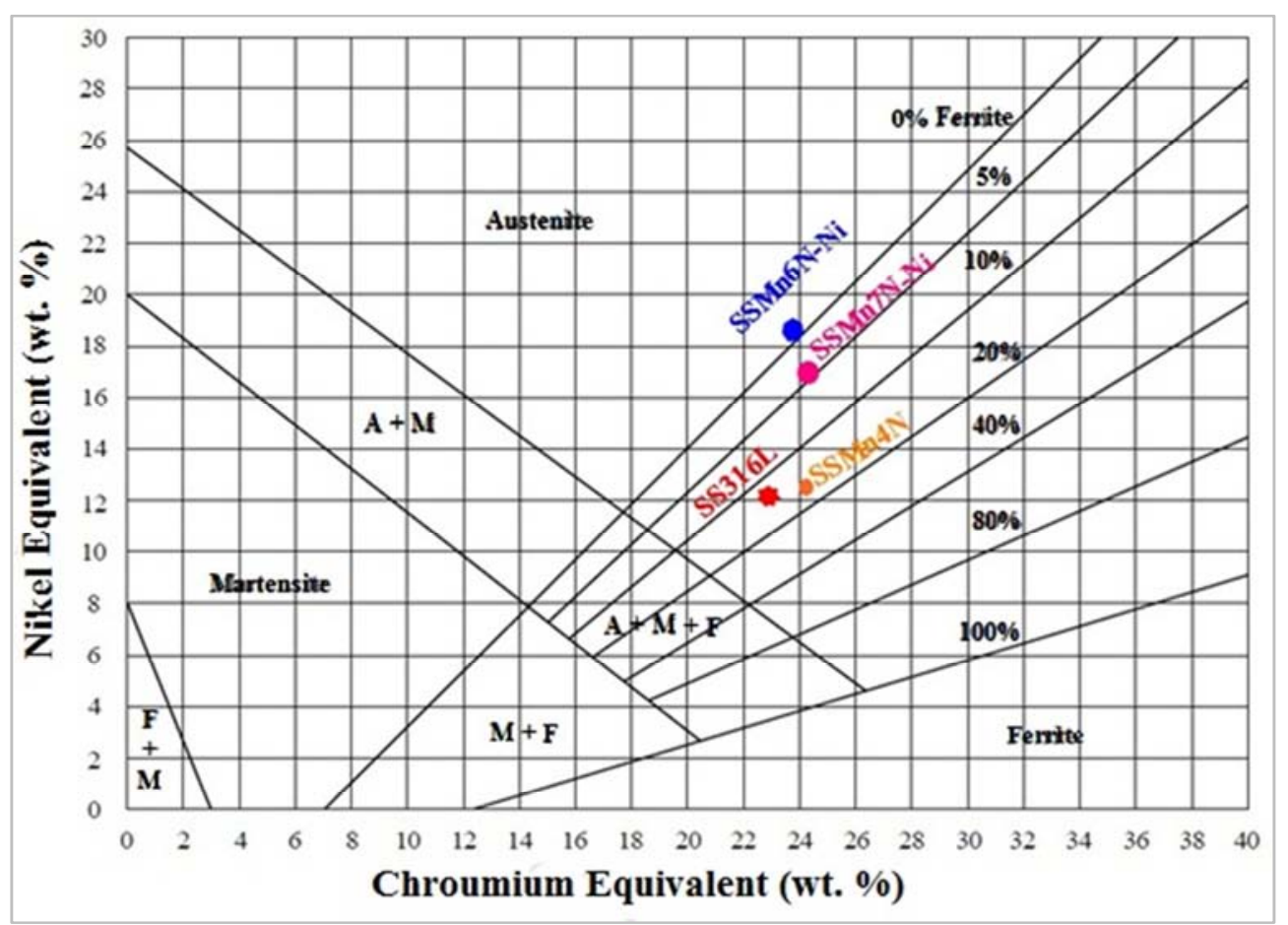

Figure 4. Schaeffler diagram of the investigated stainless steel alloys.

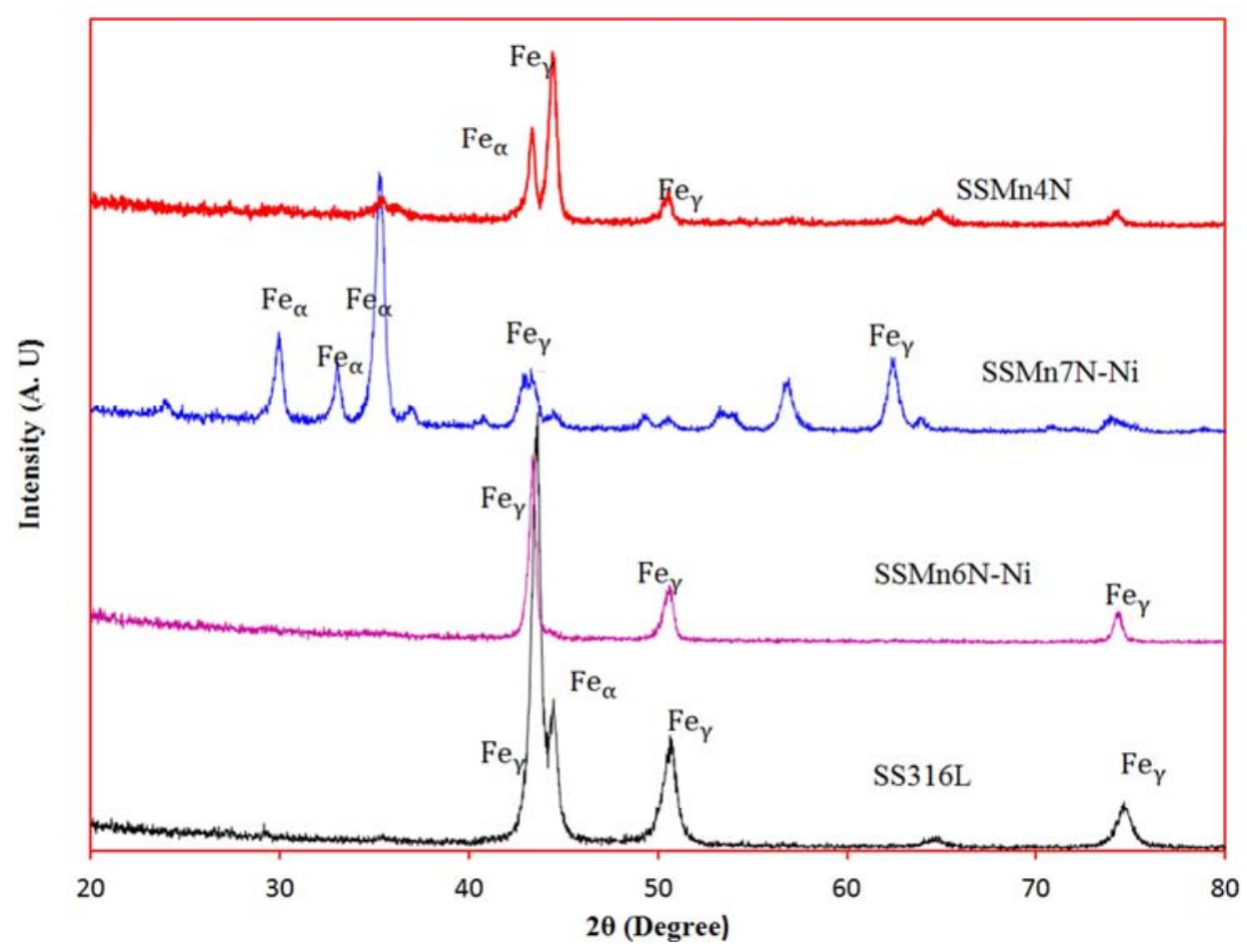

Figure 5. X-ray diffraction pattern of the investigated stainless steel alloys. 
Analysis of X-ray diffraction patterns of the studied stainless steel grads are shown in Figure 5. The modified low nickel manganese-nitrogen stainless steel (SSMn6N-Ni) shows diffraction peaks originating from the pure Face Center Cube (FCC) crystal structure only, which indicate the austenite structure of that stainless steel. The other produced stainless steel grads, SSMn7N-Ni, SSMn4N and the standard stainless steel SS316L, show a large austenite phase peaks and small peaks of ferrite phase. These observations were confirmed with the predicted results of Schaeffler diagram.

The mechanical properties, Vickers hardness, ultimate tensile strength, yield strength, elongation and impact energy were measured to study the effect of replacing nickel by manganese and nitrogen and the obtained results are displayed in Figure 6.
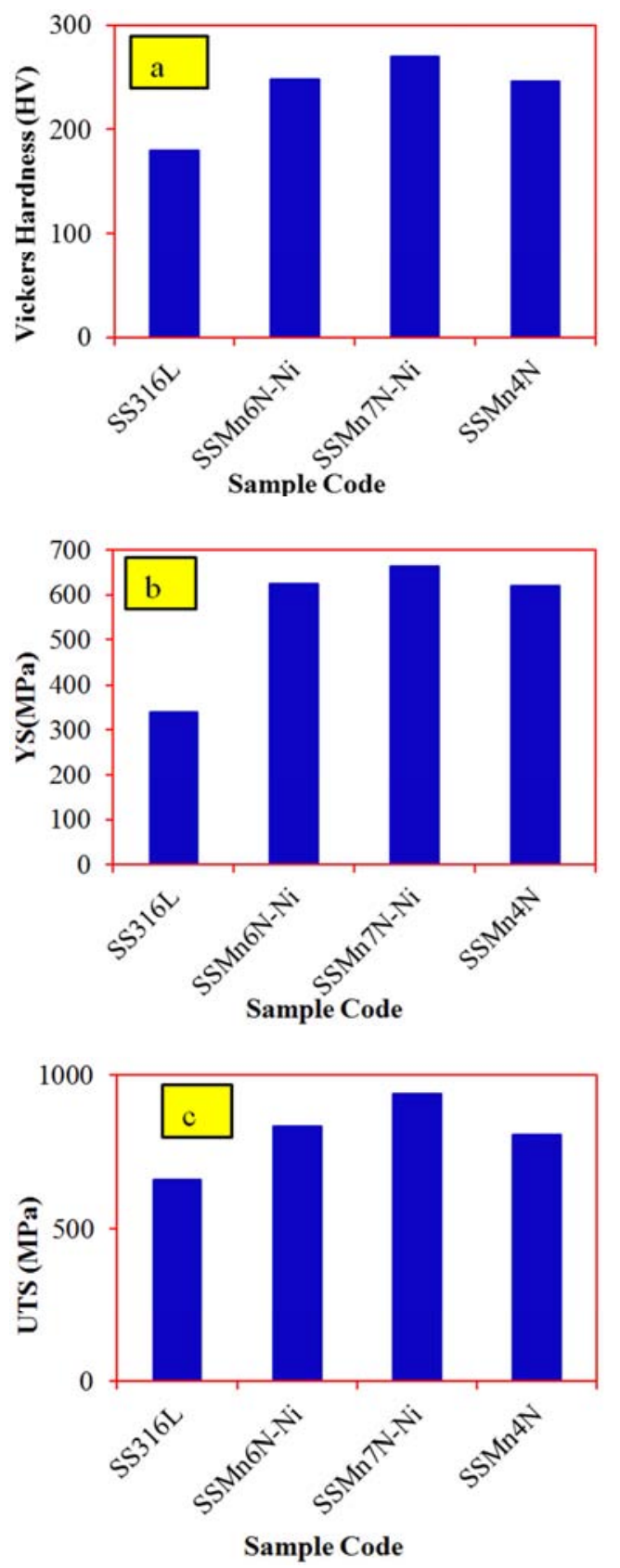
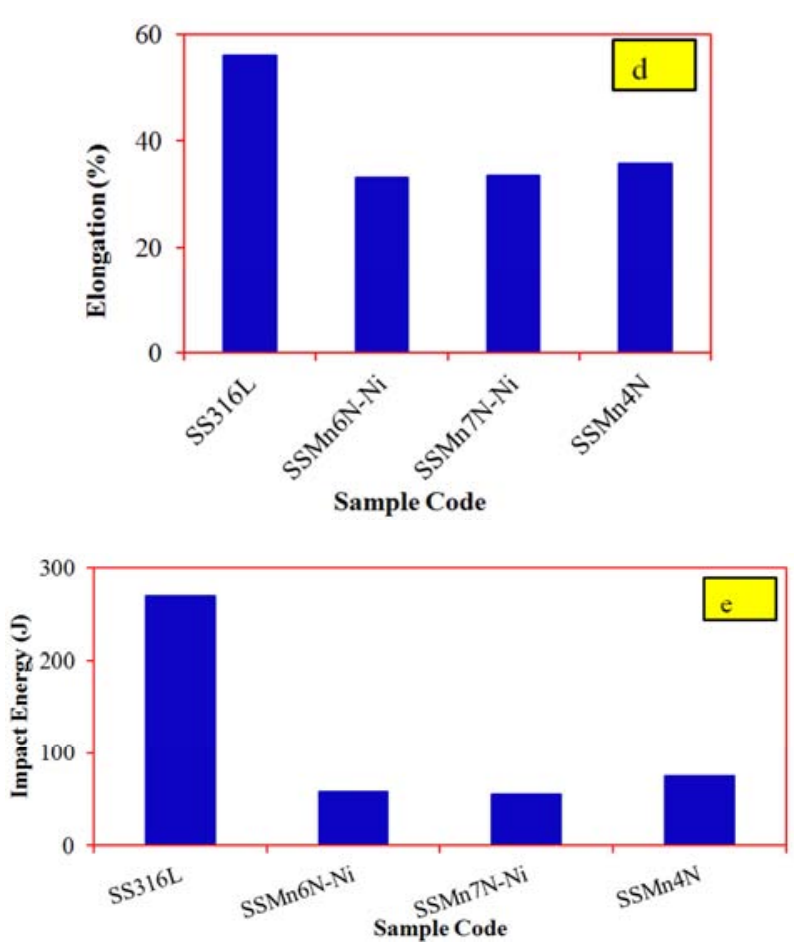

Figure 6. Mechanical properties of the investigated stainless steel alloys, a) Vickers hardness b) Yield strength c) Ultimate tensile strength d) Elongation e) Impact energy.

From Figure 6, it is observed that, the developed stainless steels, in which nickel was partially or totally replaced by manganese-nitrogen have higher hardness, yield strength and ultimate tensile strength compared with the standard AISI 316 steel (SS316). This behavior could be attributed to the solid solution strengthening mechanism of manganese. Manganese substituting iron in stainless steel crystal lattice leads to increase the load resistance of the stainless steel. Additionally, manganese imparts a higher work hardening of stainless steel alloys. Nitrogen forms an interstitial solid solution in austenite, brings about solid solution strengthening, and favors the planar dislocation slip. The strengthening is attributable to the interaction of moving dislocations with the stress field around $\mathrm{N}$ atoms in the interstices of the FCC crystal lattice. Nitrogen dissolved in the austenitic stainless steels usually enhances their strength, hardness, work hardening rate, wear resistance etc. While the elongation of the developed stainless steel alloys decreases with the increase of the manganese-nitrogen content. However, the modified high manganese stainless steel alloys still have higher ductility conforming the elongation requirement of austenitic stainless steel. The impact energy values of the investigated stainless steel grads decreases as nitrogen and manganese content is increased. Manganese and nitrogen addition in stainless steel grads was found to have a detrimental effect on toughness.

A comparison between the corrosion rate $(\mu \mathrm{m} / \mathrm{y})$ of the the modified high manganese-nitrogen stainless steels and the SS 316 L standard stainless steels in $\mathrm{NaCl}$ solution (3.5 and 5 weight $\%$ ) are given in Table 3 . The results clarify the 
superiority of the standard AISI $316 \mathrm{~L}$ stainless steel (SS316L), which has a higher nickel content, besides containing molybdenum, among all investigated steels as corrosion resistant material. However, modified stainless steels SSMn7N-Ni and SSMn4N, which have higher nitrogen content, exhibit lower corrosion rate among the modified stainless steel. The observed results were attributed to the passive film formed on the surface of sample. The passive film acts as barrier, separating the sample surface from the corrosive ions in the environment.

Table 3. Corrosion rate of the investigated steels in $3.5 w t \%$ and $5 w t \%$ $\mathrm{NaCl}$ solution.

\begin{tabular}{lll}
\hline \multirow{2}{*}{ Steel Code } & \multicolumn{2}{l}{ Corrosion rate, $\boldsymbol{\mu m} / \mathbf{y}$} \\
\cline { 2 - 3 } & in $\mathbf{3 . 5} \mathbf{w t} \% \mathbf{~ N a C l}$ & in $\mathbf{5} \mathbf{~ w t} \mathbf{~ N a C l}$ \\
\hline $\mathrm{SS} 316 \mathrm{~L}$ & 2.8 & 6.8 \\
$\mathrm{SSMn} 7 \mathrm{~N}-\mathrm{Ni}$ & 123.3 & 312.3 \\
$\mathrm{SSMn} 4 \mathrm{~N}$ & 151.9 & 408.2 \\
$\mathrm{SSMn} 6 \mathrm{~N}-\mathrm{Ni}$ & 417.8 & 1155 \\
\hline
\end{tabular}

It is clear from Table 3 that as $\mathrm{N}$ content increases the corrosion current densities decrease which indicates the improvement in the passive film stability with increasing $\mathrm{N}$ content. Therefore, Manganese has no significant influence on the corrosion resistance of stainless steels, due to the little trend to form insoluble compounds in acid medium.

The values of removal cross sections of both slow and total slow neutron (primary and that slowed down in the studied stainless steel) were deduced from the attenuation curves and are listed in Table 4. It is observed that, there is increase in the effective removal cross sections of total slow neutrons of the investigated manganese stainless steels compared with that of the standard SS316L stainless steel. Also, it was noticed that there is no significant change in the slow neutron attenuation as well as the small values of slow neutron removal cross-section. The observed behavior of slow neutron could be attributed to the absence of high slow cross section nuclei.

Table 4. Removal cross section for slow and total slow neutrons.

\begin{tabular}{lll}
\hline Sample code & $\sum_{\mathrm{T}}\left(\mathbf{c m}^{-1}\right)$ & $\sum_{\mathbf{S}}\left(\mathbf{c m}^{-\mathbf{1}}\right)$ \\
\hline SS316L & $0.162 \pm 0.035$ & $0.098 \pm 0.017$ \\
SSMn6N-Ni & $0.193 \pm 0.004$ & $0.115 \pm 0.007$ \\
SSMn7N-Ni & $0.196 \pm 0.011$ & $0.104 \pm 0.003$ \\
SSMn4N & $0.214 \pm 0.001$ & $0.093 \pm 0.007$ \\
\hline
\end{tabular}

The gamma ray attenuation coefficients of the investigated stainless steel alloys were studied for the energy range 238.63 - $2614.51 \mathrm{keV}$. The measured intensities of $\gamma$-rays transmitted through stainless steel samples were given as a function of samples thickness. The attenuation curves were used to deduce the average values of linear attenuation coefficients and hence the experimental mass attenuation coefficients $\left(\sigma_{\text {Exp. }}\right)$ were deduced. The deduced values of $\left(\sigma_{\text {Exp. }}\right)$ are listed in Table 5 and compared with the theoretical calculation of mass attenuation coefficients $\left(\sigma_{\text {Theo. }}\right)$ which were performed WinXCom computer program. It was observed that the mass attenuation coefficient nearly has the same behavior for all investigated stainless steel alloys. Also; the mass attenuation coefficients have nearly the same values for all the developed stainless steel alloys. This behavior is mainly due to the existence a balance in high Z-elements ( $\mathrm{Fe}, \mathrm{Cr}, \mathrm{Ni}$ and $\mathrm{Mn}$ ) in the studied stainless steel grads.

Table 5. Mass attenuation coefficients of the studied alloys.

\begin{tabular}{|c|c|c|c|c|c|c|c|c|}
\hline \multirow{2}{*}{$\begin{array}{l}\text { Gamma } \\
\text { Energy }(\mathrm{keV})\end{array}$} & \multicolumn{2}{|l|}{ SS316L } & \multicolumn{2}{|l|}{ SSMn6N-Ni } & \multicolumn{2}{|l|}{ SSMn7N-Ni } & \multicolumn{2}{|l|}{ SSMn4N } \\
\hline & $\sigma_{\text {Exp. }}$ & $\sigma_{\text {Theo. }}$ & $\sigma_{\text {Exp. }}$ & $\sigma_{\text {Theo. }}$ & $\sigma_{\text {Exp. }}$ & $\sigma_{\text {Theo. }}$ & $\sigma_{\text {Exp. }}$ & $\sigma_{\text {Theo. }}$ \\
\hline 238.63 & $0.118 \pm 0.001$ & 0.121 & $0.119 \pm 0.006$ & 0.119 & $0.118 \pm 0.001$ & 0.119 & $0.118 \pm 0.001$ & 0.120 \\
\hline 338.28 & $0.102 \pm 0.001$ & 0.099 & $0.101 \pm 0.002$ & 0.099 & $0.099 \pm 0.001$ & 0.099 & $0.100 \pm 0.004$ & 0.099 \\
\hline 583.19 & $0.073 \pm 0.009$ & 0.077 & $0.077 \pm 0.001$ & 0.077 & $0.075 \pm 0.006$ & 0.077 & $0.076 \pm 0.003$ & 0.077 \\
\hline 911.20 & $0.058 \pm 0.006$ & 0.062 & $0.064 \pm 0.002$ & 0.062 & $0.061 \pm 0.004$ & 0.062 & $0.062 \pm 0.001$ & 0.062 \\
\hline 968.97 & $0.058 \pm 0.001$ & 0.061 & $0.059 \pm 0.003$ & 0.060 & $0.058 \pm 0.001$ & 0.060 & $0.058 \pm 0.001$ & 0.061 \\
\hline 1173.23 & $0.053 \pm 0.008$ & 0.055 & $0.055 \pm 0.001$ & 0.055 & $0.053 \pm 0.003$ & 0.055 & $0.054 \pm 0.005$ & 0.055 \\
\hline 2614.51 & $0.036 \pm 0.002$ & 0.038 & $0.038 \pm 0.001$ & 0.038 & $0.037 \pm 0.001$ & 0.038 & $0.038 \pm 0.002$ & 0.038 \\
\hline
\end{tabular}

The observed variations in mass attenuation coefficients as shown in Table 5 can be explained by photon energy and Zdependency of interaction cross section of the elements. Two different regions were observed in behavior of mass attenuation coefficients. Firstly, there is a sharp decrease of mass attenuation coefficients in the energy range from 238.63 $\mathrm{keV}$ up to $583.19 \mathrm{keV}$ because of the dominant reaction between the investigated stainless steel grads and gamma rays is the photoelectric effect. Secondly, there is a slight decrease of mass attenuation coefficients from $911.2 \mathrm{keV}$ up to $2614.51 \mathrm{keV}$ which was attributed to the Compton scattering process. Additionally, there is a good agreement between the experimental data of mass attenuation coefficients and corresponding theoretical values calculated by WinXCom computer program (version 3.1).

\section{Conclusion}

Low activation high manganese-nitrogen austenitic stainless steel grads were produced to be used as a fast reactor pressure cladding. The modified high manganesenitrogen stainless steel SSMn6N-Ni showed mainly austenite microstructure while there is a little portion of ferrite phase in SSMn7N-Ni, SSMn4N and SS316L stainless steel grades. The developed manganese-nitrogen austenitic stainless steels have higher hardness, yield strength and ultimate tensile strength those of SS316L. In contrary, the modified high manganese-nitrogen austenitic stainless steels showed lower elongation that of SS316L. However, the modified high manganese-nitrogen stainless steel grads still have higher 
ductility. The increase of $\mathrm{N}$ content in manganese-nitrogen stainless steels decreases the corrosion current densities which indicated on the improving in the passive film stability with increasing $\mathrm{N}$ content. Manganese and nitrogen addition in stainless steel grads was found to have a detrimental effect on the impact energy; hence the impact energy should be improved. The removal cross section of total slow neutron of the modified high manganese-nitrogen steels is better than the standard SS316L stainless steel. The gamma rays mass attenuation coefficients are nearly the same for all the studied alloys. Also, very small values of slow neutron removal cross section of the developed manganese-nitrogen stainless steel were observed in comparison with SS316L stainless steel. The observed austenite phase, the good mechanical properties, the good attenuation properties as well as the low activation and cost of the modified manganese-nitrogen stainless steel alloys select them to be candidate materials for liquid sodium fast reactor pressure vessel cladding.

\section{References}

[1] Mladen Pajnić, Krunoslav Markulin, Alojzije Matokovic and Hrvoje Franjić, "Advanced Approach of Reactor Pressure Vessel In-Service Inspection" $10^{\text {th }}$ European Conference on Non-Destructive Testing, Moscow Russia, PP. 1-15, 2010.

[2] Changheui Jang, III-Seok Jeon, and Sung Yull Hong, "Treatment of Stainless Steel Cladding in Pressurized Thermal Shock Evaluation: Deterministic Analysis", Journal of the Korean Nuclear Socity, Vol. 23, No. 2, PP, 132-144, 2001.

[3] Hiroyuki Kaneko, Tokiko Nakagawa, Kousei Hiraizumi, and Ryo Sakai, "Accelerated Corrosion Tests of Nuclear Reactor Pressure Vessel Materials in $\mathrm{NaC}-\mathrm{H}_{3} \mathrm{BO}_{3}$ Solutions", Materials Transactions, Vol. 54, No. 5, PP. 755-764, 2013.

[4] E. V. Demina, L. I. Ivanov, Yu. M. Platov, M. D. Prusakova, S. R. Eikholtser, M. B. Tolochko, and F. A. Garner, "Radiation Creep and Phase Instability of Low-Activation Austenitic Steel $12 \mathrm{Cr}-20 \mathrm{Mn}-\mathrm{W}$ under Neutron Irradiation in the FFTF Fast Reactor", Inorganic Materials: Applied Research, Vol. 2, No. 5, pp. 457-460, 2011.

[5] A. Fattah-alhosseini, F. Shirsalimi, M. Yousefi and A. Abedi, "Electrochemical Behaviour Investigation of Two Low Activation Austenitic Stainless Steels in An Acidic Solution", Journal of Materials and Environmental Science, Vol. 5, No. 6, PP. 1847-1853, 2014.

[6] E. V. Demina, M. D. Prusakova, V. V. Roshchin, N. A. Vinogradova, G. D. Orlova, "Reduced Activation Fe-Cr-Mn Austenitic Steels for Nuclear Power Plants", Inorganic
Materials: Applied Research, April 2010, Volume 1, Issue 2, pp 115-124.

[7] A. Grajcar, S. Ko ${ }^{3}$ odziej, W. Krukiewicz, "Corrosion resistance of High-Manganese Austenitic Steels", Archives of Materials Science and Engineering, Vol. 41, No. 2, PP. 77-84, 2010 .

[8] M. Opiela, A. Grajcar, W. Krukiewicz, "Corrosion Behaviour of Fe-Mn-Si-Al Austenitic Steel in Chloride Solution" Journal of Achievements in Materials and Manufacturing Engineering, Vol. 33, No. 2, PP. 159-165, 2009.

[9] Linda Mosecker and Alireza Saeed-Akbari, "Nitrogen in Chromium-Manganese Stainless Steels: A Review on The Evaluation of Stacking Fault Energy by Computational Thermodynamic", Sci. Technol. Adv. Mater, Vol. 14, PP. 1-14, 2013.

[10] V. Muthukumaran, V. Selladurai, S. Nandhakumar, M. Senthilkumar, "Experimental Investigation on Corrosion and Hardness of Ion Implanted AISI 316L Stainless Steel", Materials and Design, Vol. 31, PP.2813-2817, 2010.

[11] Azza Ahmed, Saeed Ghali, Mamdouh Eissa and Salah Elbadry, "Influence of Partial Replacement of Nickel by Nitrogen on Microstructure and Mechanical Properties of Austenitic Stainless Steel", Journal of Metallurgy, Vol. 2011, PP.1-6, 2011.

[12] LI Hua-bing, Jiang Zhou-hua, Shen Ming-hui, and You Xiang-mi, International, "High Nitrogen Austenitic Stainless Steels Manufactured by Nitrogen Gas Alloying and Adding Nitrided Ferroalloys", Journal of iron and steel research, Vol. 14, No. 3, PP. 63-68, 2007.

[13] Jan-Åke Persson, Mårten Wennerholm and Stephen O'Halloran, "Handbook for Kjeldahl Digestion", FOSS, DK3400 Hilleroed, Denmark, $4^{\text {th }}$ edition, 2008.

[14] ASTM E8 / E8M-15a, "Standard Test Methods for Tension Testing of Metallic Materials", ASTM International, West Conshohocken, PA, 2015, www.astm.org.

[15] Aly Saeed, Y. H. Elbashar and R. M. El shazly, "Optical Properties of High Density Barium Borate Glass for Gamma Ray Shielding Applications", Optical and Quantum Electronics, Vol. 48, No.1, PP. 1-10, 2016.

[16] L. Gerward, N. Guilbert, K. B. Jensen, and H. Leving, "WinXCom - A Program for Calculating X-Ray Attenuation Coefficients", Radiation Physics and Chemistry, 2004, Vol. 71, PP. 653-654.

[17] A. Fattah-alhosseinia, B. Izadia and M. Asadi Asadabad, "Evaluation of Corrosion Behavior on $\mathrm{Mn}-\mathrm{Cr}$ Austenitic Steels Using 0.1 M HCl Solution", Journal of Advanced Materials and Processing, Vol.2, No. 1, 2014, 55-63. 